\title{
Patient Satisfaction and Perceived Success with a Telephonic Health Coaching Program: The Natural Experiments for Translation in Diabetes (NEXT-D) Study, Northern California, 2011
}

Sara R. Adams, MPH; Nancy C. Goler, MD; Rashel S. Sanna; Mindy Boccio, MPH; David J. Bellamy, MAOM; Susan D. Brown, PhD; Romain S. Neugebauer, PhD; Assiamira Ferrara, MD, PhD; Deanne M. Wiley; Julie A. Schmittdiel, PhD

Suggested citation for this article: Adams SR, Goler NC, Sanna RS, Boccio M, Bellamy DJ, Brown SD, et al. Patient Satisfaction and Perceived Success with a Telephonic Health Coaching Program: The Natural Experiments for Translation in Diabetes (NEXT-D) Study, Northern California, 2011. Prev Chronic Dis 2013;10:130116. DOI: http://dx.doi.org/10.5888/pcd10.130116圈.

PEER REVIEWED

\section{Abstract}

\section{Introduction}

Health coaching can improve lifestyle behaviors known to prevent or manage chronic conditions such as diabetes. However, little is known about the patient experience with telephonic coaching programs in real-world care settings. We examined patient satisfaction, patient's perceived success in achieving program goals, and the patient-level correlates of these outcomes in a voluntary telephonic coaching program at a large integrated health care delivery system in northern California.

\section{Methods}

Kaiser Permanente Northern California patients who participated in a telephonic coaching program in 2011 were sent a cross-sectional survey about their satisfaction with health coaching and perceived success with program goals. We examined associations with patient characteristics.

\section{Results}

The survey response rate was $34 \%$; analyses were based on the $32 \%$ who completed the survey. Of those who had completed 2 or more sessions $(\mathrm{n}=232[52 \%])$, most reported being satisfied $(70 \%)$ or neutral $(20 \%)$ with the program, and $71 \%$ would recommend health coaching. Healthy weight, healthful eating, and physical activity were the most common topics discussed (88\%). Adjusting for demographic characteristics, $73 \%$ of those who had 2 or more sessions reported that health coaching helped achieve their weight-related goal. Outcomes were positively correlated with patient activation but not consistently correlated with patient demographic characteristics.

\section{Conclusion}

Levels of satisfaction and perceived success with telephonic health coaching provided by a health plan were high and positively correlated with the number of sessions completed and patient activation. Voluntary telephonic health coaching programs should promote retention and assess patients' activation levels.

\section{Introduction}

Health coaching is a promising strategy for helping patients make behavior modifications that can prevent or manage diabetes and other chronic conditions $(1,2)$. Health coaching, often delivered via one-on-one telephone encounters with nonphysician providers, strengthens patient commitment to lifestyle change by using techniques such as motivational interviewing (3-8). Featuring goal-setting and enhanced coordination with health care providers, health coaching improves behaviors related to nutrition, weight management, and medication adherence $(7,9,10)$. On the 
basis of this promise, health plans and providers are offering telephonic health coaching programs both to meet the demand for healthy lifestyle support and as a care-management strategy to improve outcomes and reduce costs $(11,12)$.

In general, patients report being satisfied with medical care delivered telephonically, ie, telemedicine (13). Although several studies report high satisfaction with telephonic health coaching and specifically with coaching interventions of moderate intensity (eg, multiple sessions initiated by the coach), these programs were limited to patients with a specific condition or risk factor $(9,14,15)$. Little is known about patient satisfaction with telephonic health coaching when implemented via low-intensity, voluntary programs providing healthy lifestyle support to a general population.

As part of the Natural Experiments for Translation in Diabetes (NEXT-D) Study testing the effectiveness of population -targeted diabetes prevention and control policies, we evaluated a telephonic health coaching program providing support for healthy weight, healthful eating, physical activity, tobacco use cessation, and stress reduction to members of a large integrated health care delivery system (16). Our aim in this preliminary analysis was to examine patientcentered outcomes of coaching, such as patient satisfaction and perceived success in achieving goals, and the patientlevel correlates of these outcomes. We postulated that satisfaction and perceived success would be correlated with the coaching topic, the number of coaching sessions the patient chose to complete, and patient activation, defined as the "knowledge, skill, and confidence for self-management" (p. 1,918) (17).

\section{Methods}

\section{Study setting and population}

Kaiser Permanente Northern California (KPNC), an integrated health care delivery system of 48 medical facilities that provides comprehensive care to more than 3 million members, has provided a health coaching program through its centralized telephonic Wellness Coaching Center (WCC) since January 2010 (18). A total of 1,927 members participated in the first 18 months of the program. KPNC members are broadly representative of the local and statewide population (19).

\section{Program description}

WCC coaches support patients with 5 primary lifestyle changes: more healthful eating, increased physical activity, weight management, tobacco use cessation, and stress reduction. Through collaborative conversations, wellness coaches provide encouragement, guidance, and motivation tailored to the patients' individual interests and readiness to change. Wellness coaching is a covered benefit offered at no cost to the approximately 2 million adult KPNC members. Members are made aware of the program through referrals by KPNC providers and staff, partnerships with employers, and direct patient outreach. Participation is voluntary, although some employers have offered an incentive for participation. At the time of the survey, patients were allowed up to 4 sessions per calendar year. The program is staffed by wellness coaches who are clinical health educators trained in motivational interviewing. Motivational interviewing, a patient-centered counseling style for addressing the common problem of ambivalence about change (20), has been effective for both weight loss and substance abuse $(21,22)$. At the time of this study, all 4 wellness coaches were English-speaking and 1 was Spanish-speaking.

Patients participate by first scheduling an appointment with a wellness coach, and coaches call patients at their designated time. A typical coaching engagement consists of 1 initial session (20-30 minutes) and shorter follow-up contacts (10-20 minutes). Wellness coaches document the sessions in the member's electronic medical record (EMR) with details about the referral source (eg, physician, employer), whether the member has completed items on a preventive health checklist (eg, recommended screenings, vaccinations), the topic(s) that the member discussed, the member's readiness to change health behaviors (measured on a self-report scale from o to 10, with o being "not ready" and 10 being "very ready"), and the member's progress in reaching the health goal starting at the second session (ie, plan attempted, completed, or not attempted). Wellness coaches are able to directly coordinate care with members' KPNC physicians (eg, requesting a prescription for smoking cessation medications) and refer members to other supportive KPNC services (eg, health education classes).

\section{Survey methods}

We conducted a cross-sectional, observational survey of patients who had their first wellness coaching session between January 1, 2011, and August 23, 2011. Patients were excluded from the survey if their primary language was not English, the patient had recently died, the patient had previously requested not to be contacted for research activities, or the patient's primary address was not in California. We administered the survey with an adapted Dillman method (23): an initial survey and cover letter were mailed in October 2011, followed 1 week later by a reminder letter and 3 weeks later by a reminder cover letter and a second copy of the survey. Patients had the choice to complete the 4-page survey on paper or online.

We present the frequency of outcomes stratified by the individual topic discussed (healthy weight, healthful eating, physical activity, tobacco use cessation, and stress reduction) and by a summary variable indicating that any of the 
weight-related topics were discussed (namely, healthy weight, healthful eating, or physical activity). Patients were determined to have discussed a topic if they marked that topic on the survey or the wellness coach had indicated that topic was discussed at any session. The survey contained 2 outcome domains: patient satisfaction (ie, overall satisfaction and willingness to recommend the program) and perceived success (ie, patient report of whether wellness coaching helped with goal achievement). The first outcome was a 3-level indicator for satisfaction (respondent indicated being satisfied/extremely satisfied vs neutral vs dissatisfied/extremely dissatisfied to the question, "Overall, how satisfied are you with the service you received from the Wellness Coach?”). The second outcome was a 3-level indicator for willingness to recommend the program (agree/strongly agree vs neither agree or disagree vs disagree/strongly disagree with the statement, "I would recommend Wellness Coaching to a family member, friend or colleague"). The third outcome was perceived success of health coaching for those who called to discuss a weightrelated topic, coded as a dichotomous variable ( 1 for yes to the question "Did Wellness Coaching help?" for any of the 3 weight-related topics, $\mathrm{o}$ if the respondent indicated no, don't know, or left the question blank). In addition, patients were asked if their reasons for participating in wellness coaching included to "improve your health," "improve your quality of life," "reduce your risk of disease," or "address a recent health concern" and whether wellness coaching helped with these goals.

The survey solicited information about patient demographics (race/ethnicity, education, and income) and patient activation as measured by the Patient Activation Measure 6 (PAM-6) (24), a version of the well-validated Patient Activation Measure 13 (17) that was modified by the developers. Patient activation has been positively correlated with healthy behaviors, better health outcomes, and better health care experiences (25). We expected the level of patient activation to be positively correlated with program satisfaction and perceived success (26). Raw PAM-6 scores were mapped to 4 patient activations levels: "May not yet believe that the patient role is important" (level 1); "Lacks confidence and knowledge to take action" (level 2); "Beginning to take action" (level 3); and "Has difficulty maintaining behaviors over time" (level 4) (24).

Additional patient characteristics for respondents and nonrespondents, including age at the first coaching session, sex, race/ethnicity, and body mass index (BMI; calculated as the weight in kilograms divided by the height in meters squared) at the most recent visit before the first coaching session, were obtained from the EMR. Because the EMR does not contain individual-level socioeconomic variables, we created categorical variables representing the median annual household income ( $<$ \$0,000; $\$ 30,000-\$ 79,999$; $\$ 80,000-\$ 119,999$, or $\geq \$ 120,000)$ and average educational attainment $(<15 \%, 15 \%-29 \%, 30 \%-44 \%$, or $\geq 45 \%$ with a bachelor's degree) for each patient's US Census 2000 block group of residence. The dates and topics of the wellness coaching sessions were assessed from the EMR at the time of the first survey mailing.

The patient activation measure is associated with key process and health outcomes measures (27). On the basis of this, we conservatively calculated that a sample size of 436 would be sufficient to determine a 5-point difference in mean PAM-6 scores between women and men or between respondents discussing weight-related topics and those discussing other topics, using an estimate that the ratio of women to men and the ratio of weight-related topics discussed to other topics would both be 3:1. The sample size calculation was based on an $\alpha$ level of .05 (2-tailed), 80\% power, and PAM-6 standard deviation of 16.1 .

\section{Statistical analyses}

Two sample $t$ tests, $F$ tests, and Pearson $\chi^{2}$ tests of independence were used to compare the characteristics of respondents with those of nonrespondents. We used Pearson $\chi^{2}$ tests of independence to assess bivariate associations between survey outcome measures and the categorical indicators: sex, race/ethnicity (non-Hispanic white vs other/missing), number of sessions (1 vs $\geq 2$ ), and topic of first wellness coaching session (weight-related topic vs other/missing). We calculated mean age, BMI, and PAM-6 activation scores per stratified outcome level (eg, the mean age for patients who reported being satisfied was compared with the mean age for patients who reported being dissatisfied), and evaluated potential associations with $t$ tests and $F$ tests. All tests were 2-sided with an a level of .05 to determine significance.

The predicted percentages of patients reporting satisfaction and perceived success with wellness coaching were generated from logistic regression models in which patient characteristics (age, sex, race/ethnicity, BMI, education, income, PAM-6 activation level, and number of sessions) were set to their mean or proportional values. We also calculated predicted percentages for all patients who discussed a weight-related topic and stratified by the patient characteristics that consistently correlated with the outcome variables in the bivariate analyses. We used SAS software versions 9.1.3 and 9.3 (SAS Institute Inc, Cary, North Carolina) for all data management and analysis. The KPNC Institutional Review Board approved this study.

\section{Results}

Of the 1,539 patients who had their first wellness coaching session during the study period, 112 were excluded from the eligible survey cohort because they had a primary language other than English $(n=101)$, had previously requested to 
be excluded from research $(n=6)$, had recently died $(n=2)$, or had a primary mailing address not in California $(n=3)$. The remaining patients $(n=1,427)$ met the inclusion criteria and were sent the initial mailing. Of these, 17 people were later determined to be ineligible due to undelivered survey $(n=15)$, recent death $(n=1)$, or not being a KPNC member $(n=1)$. A total of 486 patients returned a survey; the resulting response rate was $34 \%(486 / 1,410)$. Respondents and nonrespondents were similar with regard to sex, geocoded education, and topic of first wellness coaching session. Compared with nonrespondents, respondents to the survey were more likely to be older, to be white, to have lower BMI, and to have attended more than 1 WCC session (Table 1). Participation in wellness coaching had been identified through the EMR, yet when asked "Have you had any phone calls with a Kaiser Permanente Wellness Coach?" 40 respondents indicated no, don't know, or "I choose not to answer this question" and did not complete the rest of the survey. The main analyses were based on the remaining 446 respondents.

Of the people who had participated in wellness coaching and completed the survey, most were women (83\%), of white race/ethnicity (53\%), and overweight (25\%) or obese (57\%) (Table 1). Most discussed a weight-related topic at their first coaching session (82\%). A total of 232 patients (52\% of the analysis cohort; $16 \%$ of all patients who were mailed a survey) had completed more than 1 coaching session at the time of the survey.

In the overall sample, most respondents indicated that they were satisfied or extremely satisfied (60\%) or neutral (24\%) with the service received from the wellness coach (Table 2), and 64\% would recommend wellness coaching to others. Most respondents were more aware of Kaiser Permanente resources (57\%) and more likely to participate in other Kaiser Permanente programs (54\%) after speaking with a wellness coach. Most patients reported that wellness coaching helped them achieve their goal (50\%-62\%, depending on the topic). Respondents with 2 or more sessions were more likely than respondents with 1 session to be satisfied $(P<.001)$ and to recommend wellness coaching $(P$ $=.007)$. Respondents who completed 2 or more sessions were more likely to report that wellness coaching helped them to eat more healthfully ( $68 \%$ vs $54 \%, P=.04$ ), increase their physical activity ( $71 \%$ vs $45 \%, P<.001)$, improve their health ( $79 \%$ vs $61 \%, P=.005)$, improve their quality of life ( $83 \%$ vs $61 \%, P<.001)$, and reduce their risk of disease (73\% vs $51 \%, P=.01)$.

PAM-6 scores significantly increased with increasing levels of satisfaction and likelihood of recommending the WCC program (Table 3). The patients who reported that wellness coaching helped them achieve their weight-related goal also had significantly higher PAM-6 scores compared with those who did not report that wellness coaching helped.

Satisfaction and perceived success were not consistently correlated with the other indicators tested (ie, sex, race/ethnicity, topic of first session, age, and BMI). The few exceptions were that satisfied respondents tended to be older than those who were not satisfied (mean [standard deviation] 58 [14] years vs 54 [14] years, $P=.01$ ), and white respondents were more likely than nonwhite respondents to recommend wellness coaching to others ( $71 \%$ vs $55 \%, P$ $=$.002). Men were also more likely than women to report being more aware of Kaiser Permanente resources after wellness coaching ( $74 \%$ vs $54 \%, P=.005)$.

Predicted percentages of the primary outcomes were calculated for the overall cohort as well as stratified by the number of sessions completed (1 vs $\geq 2$; Figure 1) and PAM-6 activation level (levels 1-4; Figure 2). After controlling for the number of sessions, age, sex, race/ethnicity, BMI, education, and income, patients at the highest activation level were significantly more likely than those at the lowest activation level to report that they were satisfied with the program ( $77 \%$ vs $37 \%, P<.001)$ and that wellness coaching helped them address a weight-related goal $(79 \%$ vs $45 \%, P$ $<.001)$. 


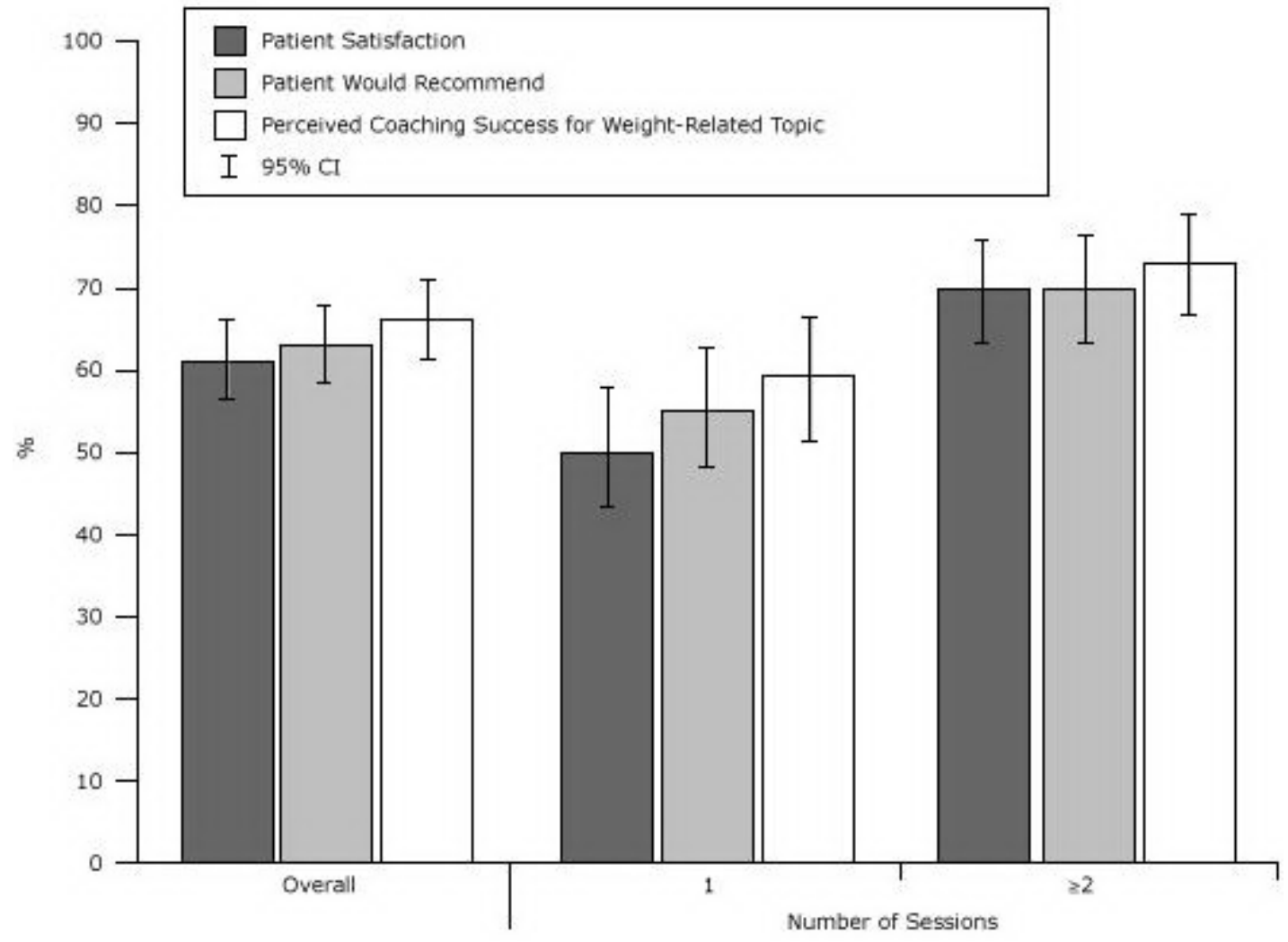

Figure 1. Predicted percentage of patient satisfaction and perceived success for a weight-related topic, stratified by the number of coaching sessions completed, Kaiser Permanente Wellness Coaching Program Survey, northern California, 2011. Percentages are adjusted for age, sex, race/ethnicity, body mass index, education, and income. Abbreviation: $\mathrm{Cl}$, confidence interval. [A tabular version of this figure is also available.]

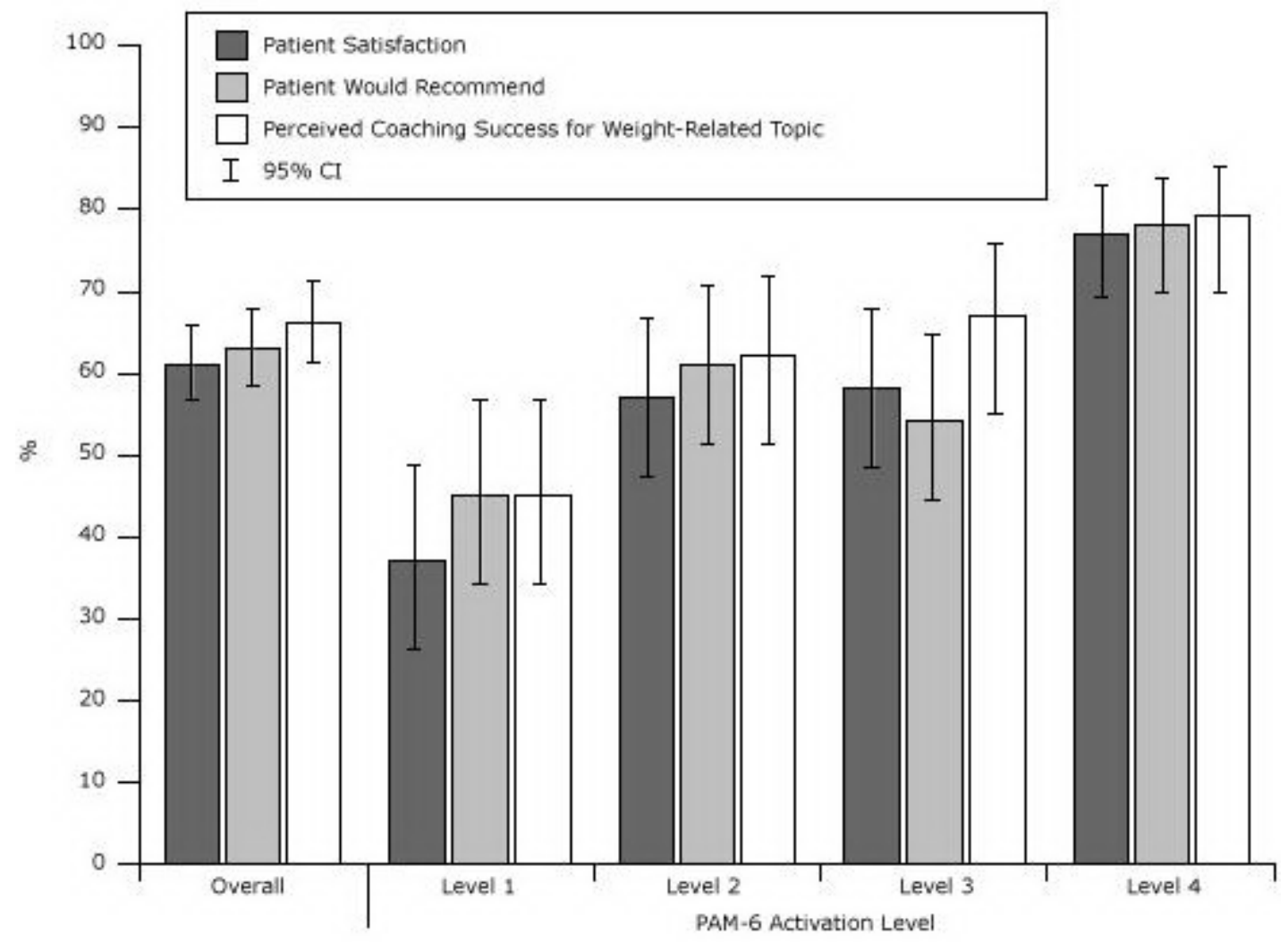


Figure 2. Predicted percentage of patient satisfaction and perceived success for a weight-related topic, stratified by Patient Activation Measure 6 (PAM-6) (24) activation level, Kaiser Permanente Wellness Coaching Program Survey, northern California, 2011. Percentages are adjusted for age, sex, race/ethnicity, body mass index, education, and income. Abbreviation: $\mathrm{Cl}$, confidence interval. [A tabular version of this figure is also available.]

\section{Discussion}

Our survey of Kaiser Permanente patients participating in a health coaching program indicated most were satisfied with the program and believed that coaching had helped them achieve their health-related goals. These patientreported satisfaction and success measures were positively correlated with the number of coaching sessions completed but not consistently correlated with age, sex, race/ethnicity, BMI, education, income, or the topics discussed. Previously published studies have only looked at satisfaction with health coaching when it was delivered as part of a multifaceted wellness program (28) or focused on a small group with a specific disease that received more intensive coaching $(9,14,15,29)$. Our study is the first to assess satisfaction with voluntary health coaching offered to all adult members of a health plan regardless of pre-existing comorbidities. Our results suggest that population-based telephonic coaching programs can be an effective approach to helping patients achieve their wellness goals.

Our study found that patients attending 2 or more coaching sessions were more satisfied with the coaching program and reported higher levels of self-perceived success. Many patients in this study attended only 1 coaching session out of the 4 that they were eligible to attend. It is unclear if more motivated patients signed up for further visits or if that by attending more visits, they were further motivated to change. Although these results are cross-sectional and cannot determine causality, our study suggests voluntary coaching programs should focus on retention to improve success. This relationship would be important to discern in future studies.

After controlling for demographic variables, patients at the highest activation level were significantly more likely than those at the lowest activation level to report that they were satisfied with the program and that wellness coaching helped them address a weight-related goal. Because patient activation was not measured at baseline, we cannot determine whether patient's activation levels were influenced by wellness coaching participation. Coaching programs may benefit from measuring patient activation before and following coaching participation to tailor the coaching interaction to the patient's activation level and to study whether wellness coaching modifies activation levels.

Several limitations should be noted. The survey response rate was low (34\%), and respondents differed from nonrespondents in age, race/ethnicity, BMI, and number of sessions attended. Although outcomes were not correlated with age, race/ethnicity, or BMI, the results may be biased because nonrespondents were more likely than respondents to have attended only 1 WCC session, and attending more coaching sessions was associated with higher satisfaction and perceived success. Participants in the WCC program were predominantly women and approximately half were white, and this limits the generalizability of our findings to all patients who participate in coaching programs. A small number of participants may have received an incentive from their employer to enroll in the voluntary WCC program. In addition, our survey was cross-sectional and therefore we cannot determine causality. Some of the patients were surveyed more than 6 months after their initial session, so their impression of wellness coaching might have been influenced by other factors in the time following their interaction with a wellness coach. Satisfaction with health care is an important patient-centered outcome (30), but objective clinical outcomes should also be examined. Further studies of WCC participants will evaluate success based on clinical measures available in the EMR (ie, BMI and systolic blood pressure).

Health coaching is a population-based approach to encourage healthy lifestyle choices and prevent chronic disease that has been embraced by health care delivery systems. Our study found that levels of satisfaction and perceived success with health coaching provided by a health plan were high and positively correlated with the number of sessions completed and patient activation. Health coaching appears promising but needs to be studied further to maximize health promotion outcomes.

\section{Acknowledgments}

This study was funded by the Centers for Disease Control and Prevention and the National Institute of Diabetes and Digestive and Kidney Diseases (NIDDKD) (no. U58 DPo02721). Drs Ferrara and Schmittdiel were also supported by the Health Delivery Systems Center for Diabetes Translational Research (NIDDKD grant no. 1P30-DKo92924).

\section{Author Information}

Corresponding Author: Sara R. Adams, MPH, Division of Research, Kaiser Permanente Northern California, 2000 Broadway, Oakland, CA 94612. Telephone: 510-891-3133. E-mail: Sara.R.Adams@kp.org. 
Author Affiliations: Nancy C. Goler, Rashel S. Sanna, Mindy Boccio, David J. Bellamy, Susan D. Brown, Romain S. Neugebauer, Assiamira Ferrara, Deanne M. Wiley, Julie A. Schmittdiel, Kaiser Permanente Northern California, Oakland, California.

\section{References}

1. Diabetes Prevention Program Research Group; Knowler WC, Fowler SE, Hamman RF, Christophi CA, Hoffman HJ, et al. 10-year follow-up of diabetes incidence and weight loss in the Diabetes Prevention Program Outcomes Study. Lancet 2009;374(9702):1677-86. Erratum in Lancet 2009;374(9707):2054. CrossRef ⿴囗大ㅇ PubMed 因

2. Grundy SM, Garber A, Goldberg R, Havas S, Holman R, Lamendola C, et al. Prevention Conference VI: Diabetes and Cardiovascular Disease: Writing Group IV: lifestyle and medical management of risk factors. Circulation 2002;105(18):e153-8. CrossRef 圈 PubMed 圈

3. Butterworth S, Linden A, McClay W, Leo MC. Effect of motivational interviewing-based health coaching on

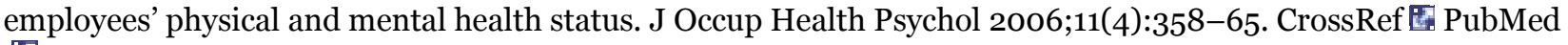
因

4. Miller WR, Rollnick S. Ten things that motivational interviewing is not. Behav Cogn Psychother 2009;37(2):12940. CrossRef 圈 PubMed 圈

5. Bennett H, Laird K, Margolius D, Ngo V, Thom DH, Bodenheimer T. The effectiveness of health coaching, home blood pressure monitoring, and home-titration in controlling hypertension among low-income patients: protocol for a randomized controlled trial. BMC Public Health 2009;9:456. CrossRef PubMed 因

6. Bennett HD, Coleman EA, Parry C, Bodenheimer T, Chen EH. Health coaching for patients with chronic illness. Fam Pract Manag 2010;17(5):24-9. PubMed 专

7. Olsen JM, Nesbitt BJ. Health coaching to improve healthy lifestyle behaviors: an integrative review. Am J Health Promot 2010;25(1):e1-12. CrossRef 圈 PubMed 圈

8. Huffman MH. Health coaching: a fresh, new approach to improve quality outcomes and compliance for patients with chronic conditions. Home Healthc Nurse 2009;27(8):490-6. CrossRef E PubMed 恩

9. Hutchison AJ, Breckon JD. A review of telephone coaching services for people with long-term conditions. J Telemed Telecare 2011;17(8):451-8. CrossRef 圈 PubMed 圈

10. Goode AD, Reeves MM, Eakin EG. Telephone-delivered interventions for physical activity and dietary behavior change: an updated systematic review. Am J Prev Med 2012;42(1):81-8. CrossRef 国 PubMed 圈

11. Wennberg DE, Marr A, Lang L, O’Malley S, Bennett G. A randomized trial of a telephone care-management strategy. N Engl J Med 2010;363(13):1245-55. CrossRef 国 PubMed 国

12. Byrnes JM, Goldstein S, Venator B, Pollicino C, Ng SK, Veroff D, et al. The impact of population-based disease management services for selected chronic conditions: the Costs to Australian Private Insurance - Coaching Health (CAPICHe) study protocol. BMC Public Health 2012;12:114. CrossRef $\mathrm{E}$ PubMed 国

13. Heinzelmann PJ, Williams CM, Lugn NE, Kvedar JC. Clinical outcomes associated with telemedicine/telehealth. Telemed J E Health 2005;11(3):329-47. CrossRef 圈 PubMed 圈

14. Hawkes AL, Gollschewski S, Lynch BM, Chambers S. A telephone-delivered lifestyle intervention for colorectal cancer survivors 'CanChange': a pilot study. Psychooncology 2009;18(4):449-55. CrossRef 国 PubMed 圈

15. Whittemore R, Melkus GD, Sullivan A, Grey M. A nurse-coaching intervention for women with type 2 diabetes. Diabetes Educ 2004;30(5):795-804. CrossRef 圈 PubMed 圈

16. Schmittdiel JA, Brown SD, Neugebauer R, Adams SR, Adams AS, Wiley D, et al. Health-plan and employer-based wellness programs to reduce diabetes risk: the Kaiser Permanente Northern California NEXT-D study. Prev Chronic Dis 2013;10:E15. http://www.cdc.gov/pcd/issues/2013/12_0146.htm. Accessed March $15,2013$. CrossRef 圈 PubMed 圈

17. Hibbard JH, Mahoney ER, Stockard J, Tusler M. Development and testing of a short form of the Patient Activation Measure. Health Serv Res 2005;40(6 Pt 1):1918-30. CrossRef 圈 PubMed 圈

18. Wellness coaching. Oakland (CA): The Permanente Medical Group, Inc. http://kp.org/mydoctor/wellnesscoaching. Accessed June 6, 2013.

19. Gordon NP. Similarity of the adult Kaiser Permanente membership in Northern California to the insured and general population in Northern California: statistics from the 2007 California Health Interview Survey. Oakland (CA): Kaiser Permanente Northern California Division of Research; 2012. http://www.dor.kaiser.org/external/chis_non_kp_2007. Accessed June 6, 2013.

20. Miller WR, Rollnick S. Motivational interviewing: helping people change. Third edition. New York (NY): Guilford Press; 2013. 
21. Armstrong MJ, Mottershead TA, Ronksley PE, Sigal RJ, Campbell TS, Hemmelgarn BR. Motivational interviewing to improve weight loss in overweight and/or obese patients: a systematic review and meta-analysis of randomized controlled trials. Obes Rev 2011;12(9):709-23. PubMed 国

22. Dunn C, Deroo L, Rivara FP. The use of brief interventions adapted from motivational interviewing across behavioral domains: a systematic review. Addiction 2001;96(12):1725-42. CrossRef : PubMed 国

23. Dillman DA, Smyth JD, Christian LM. Internet, mail, and mixed-mode surveys: the tailored design method. Third edition. Hoboken (NJ): Wiley and Sons; 2009.

24. Patient Activation Measure (PAM) 6 license materials. Portland (OR): Insignia Health LLC; 2011.

25. Hibbard JH, Greene J. What the evidence shows about patient activation: better health outcomes and care experiences; fewer data on costs. Health Aff (Millwood) 2013;32(2):207-14. CrossRef 圈 PubMed 圈

26. Hibbard JH, Greene J, Tusler M. Improving the outcomes of disease management by tailoring care to the patient's level of activation. Am J Manag Care 2009;15(6):353-6o. PubMed 囦

27. Mosen DM, Schmittdiel J, Hibbard J, Sobel D, Remmers C, Bellows J. Is patient activation associated with outcomes of care for adults with chronic conditions? J Ambul Care Manage 2007;30(1):21-9. CrossRef 圈 PubMed 国

28. Ovbiosa-Akinbosoye OE, Long DA. Wellness program satisfaction, sustained coaching participation, and achievement of health goals. J Occup Environ Med 2012;54(5):592-7. CrossRef 国 PubMed 国

29. Leahey TM, Wing RR. A randomized controlled pilot study testing three types of health coaches for obesity treatment: professional, peer, and mentor. Obesity (Silver Spring) 2012; June 25. CrossRef 圈 PubMed 圈

30. Funding announcement: assessment of prevention, diagnosis, and treatment options. Washington (DC): PatientCentered Outcomes Research Institute; 2012. http://www.pcori.org/assets/PFA-Assessment-of-Options05222012.pdf. Accessed June 6, 2013.

\section{Tables}

Table 1. Patient Characteristics for the Respondents and Nonrespondents to the Kaiser Permanente Wellness Coaching Program Survey, Northern California, 2011

\begin{tabular}{|c|c|c|c|}
\hline Characteristic & $\begin{array}{c}\text { Respondents }(n= \\
446)\end{array}$ & $\begin{array}{c}\text { Nonrespondents }(n= \\
924)\end{array}$ & $\begin{array}{c}P \\
\text { Valuea }\end{array}$ \\
\hline Female, n (\%) & $372(83)$ & $741(80)$ & .15 \\
\hline Age, y, mean (SD) & $56(14)$ & $48(14)$ & $<.001$ \\
\hline $18-39, \mathrm{n}(\%)$ & $59(13)$ & $261(28)$ & \multirow{5}{*}{$<.001$} \\
\hline $40-49, \mathrm{n}(\%)$ & $80(18)$ & $217(23)$ & \\
\hline $50-59, \mathrm{n}(\%)$ & $116(26)$ & $250(27)$ & \\
\hline $60-69, \mathrm{n}(\%)$ & $121(27)$ & $142(15)$ & \\
\hline$\geq 70, \mathrm{n}(\%)$ & $70(16)$ & $54(6)$ & \\
\hline \multicolumn{3}{|l|}{ Race/ethnicity, n (\%) } & \multirow{7}{*}{.003} \\
\hline White/Caucasian, non-Hispanic & $236(53)$ & $392(42)$ & \\
\hline Black/African American, non-Hispanic & $57(13)$ & $151(16)$ & \\
\hline Spanish/Hispanic/Latino & $48(11)$ & $113(12)$ & \\
\hline Asian/Native Hawaiian/Pacific Islander, non-Hispanic & $26(6)$ & $72(8)$ & \\
\hline Other or multiracial, non-Hispanic & $24(5)$ & $37(4)$ & \\
\hline Unknown/choose not to answer & $55(12)$ & $159(17)$ & \\
\hline Body mass index, ${ }^{b}$ mean (SD) & $32.4(8.0)$ & $33.7(8.8)$ & .007 \\
\hline$<25$ (normal), n (\%) & $68(15)$ & $108(12)$ & \multirow[t]{2}{*}{.02} \\
\hline 25-29 (overweight), n (\%) & $111(25)$ & $217(23)$ & \\
\hline
\end{tabular}




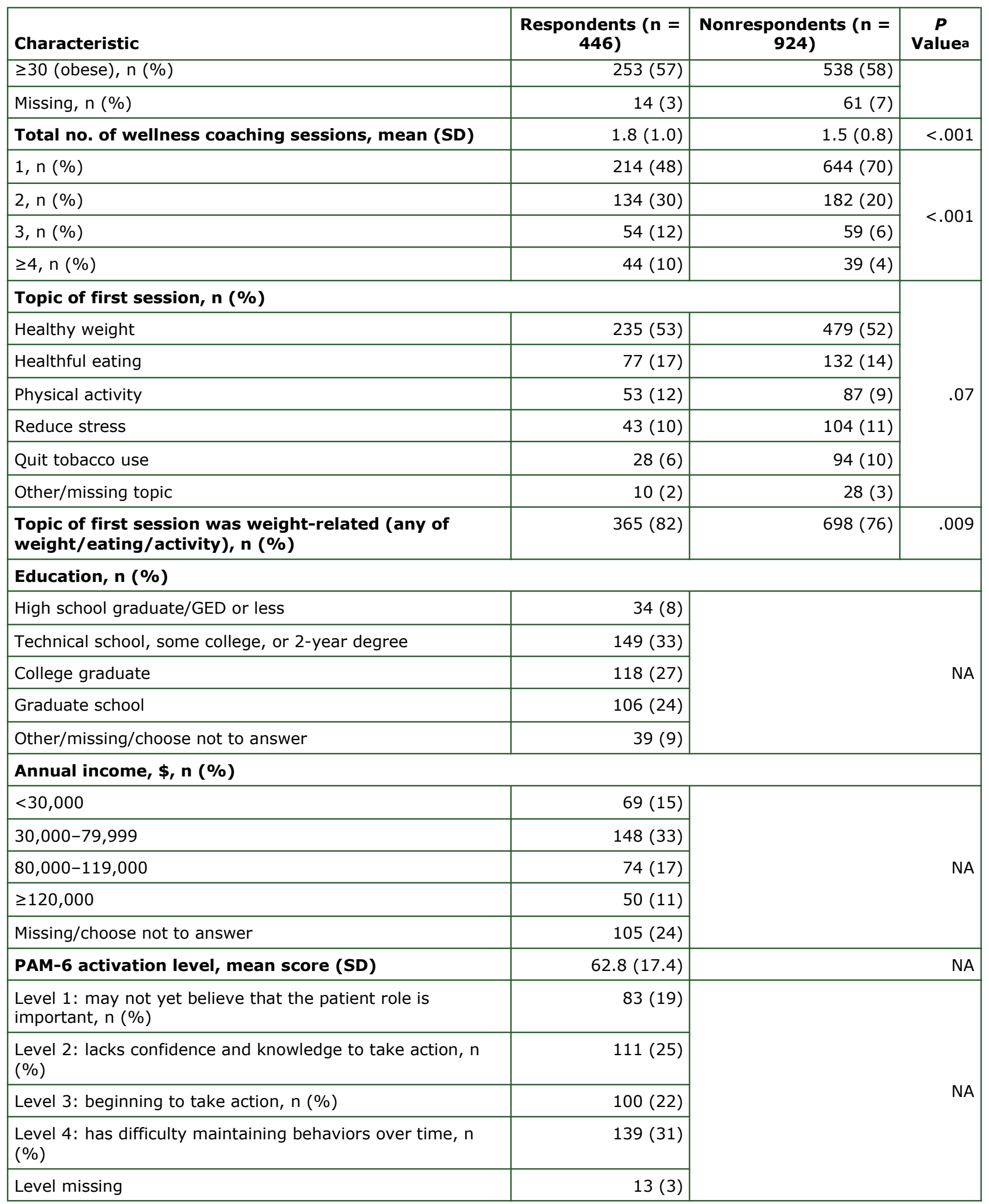

Abbreviation: SD, standard deviation; NA, not applicable; GED: general educational development certificate; PAM, Patient Activation Measure 6 (24).

a Determined by a $\mathrm{X}^{2}$ test for the difference in proportions or a $t$ test for the difference in means.

b BMI is calculated as weight in kilograms divided by height in meters squared. 
Preventing Chronic Disease | Patient Satisfaction and Perceived Success with a Teleph... Page 10 of 12

Table 2. Survey Results for Respondents $(n=446)$ to the Kaiser Permanente Wellness Coaching Program Survey, Overall and Stratified by the Number of Sessions Completed, Northern California, 2011

\begin{tabular}{|c|c|c|c|c|}
\hline Characteristic & Overall, N (\%) & 1 Session, $N(\%)$ & $\geq 2$ Sessions, $N(\%)$ & $P$ Valuea \\
\hline \multicolumn{5}{|c|}{ Satisfaction outcomes } \\
\hline \multicolumn{5}{|c|}{ Patient's overall satisfaction with the service received from the wellness coachb } \\
\hline Satisfied/extremely satisfied & $264(60)$ & $104(50)$ & $160(70)$ & \multirow{3}{*}{$<.001$} \\
\hline Neutral & $104(24)$ & $59(28)$ & $45(20)$ & \\
\hline Dissatisfied/extremely dissatisfied & $70(16)$ & $45(22)$ & $25(11)$ & \\
\hline \multicolumn{5}{|c|}{ Patient would recommend wellness coaching to a family member, friend, or colleagueb } \\
\hline Agree/strongly agree & $273(64)$ & $114(56)$ & $159(71)$ & \multirow{3}{*}{.007} \\
\hline Neither agree or disagree & $83(19)$ & $45(22)$ & $38(17)$ & \\
\hline Disagree/strongly disagree & $71(17)$ & $43(21)$ & $28(12)$ & \\
\hline \multicolumn{5}{|c|}{ Patient reported the following was adequate: } \\
\hline Number of sessions offered & $225(50)$ & $92(43)$ & $133(57)$ & .002 \\
\hline Amount of time spent with the coach & $319(72)$ & $140(65)$ & $179(77)$ & .006 \\
\hline \multicolumn{5}{|c|}{ Perceived success outcomes } \\
\hline \multicolumn{5}{|c|}{ Topic discussed with a wellness coach } \\
\hline Healthy weight & $321(72)$ & $145(68)$ & $176(76)$ & .06 \\
\hline Healthful eating & $203(46)$ & $92(43)$ & $111(48)$ & .30 \\
\hline Physical activity & $181(41)$ & $77(36)$ & $104(45)$ & .06 \\
\hline Weight-related (any of 3 listed above) & $392(88)$ & $185(86)$ & $207(89)$ & .37 \\
\hline Reduce stress & $100(22)$ & $43(20)$ & $57(25)$ & .26 \\
\hline Quit tobacco use & $34(8)$ & $13(6)$ & $21(9)$ & .24 \\
\hline \multicolumn{5}{|c|}{ Patient reported wellness coaching helped for the following topics (among those who discussed the topic) } \\
\hline Achieve or maintain a healthy weight & $141(44)$ & $60(41)$ & $81(46)$ & .40 \\
\hline Eat more healthfully & $126(62)$ & $50(54)$ & $76(68)$ & .04 \\
\hline Increase physical activity & $109(60)$ & $35(45)$ & $74(71)$ & $<.001$ \\
\hline Weight-related (any of 3 above) & $232(59)$ & $95(51)$ & $137(66)$ & .003 \\
\hline Reduce stress & $50(50)$ & $17(40)$ & $33(58)$ & .07 \\
\hline Quit tobacco use & $18(53)$ & $7(54)$ & $11(52)$ & .93 \\
\hline \multicolumn{5}{|c|}{ Patient reported wellness coaching helped (among those who gave that reason for participating) } \\
\hline Improve health & $158(71)$ & $59(61)$ & $99(79)$ & .005 \\
\hline Improve quality of life & $131(73)$ & $48(61)$ & $83(83)$ & $<.001$ \\
\hline Reduce risk of disease & $81(62)$ & $33(51)$ & $48(73)$ & .01 \\
\hline Address a recent health concern & $77(62)$ & $28(53)$ & $49(69)$ & .07 \\
\hline \multicolumn{5}{|c|}{ Other outcomes } \\
\hline \multicolumn{5}{|c|}{ Patient was more aware of Kaiser Permanente resources after wellness coachingb } \\
\hline Agree/strongly agree & $248(57)$ & $111(53)$ & $137(61)$ & .02 \\
\hline
\end{tabular}


Preventing Chronic Disease | Patient Satisfaction and Perceived Success with a Teleph... Page 11 of 12

\begin{tabular}{|c|c|c|c|c|}
\hline Characteristic & Overall, N (\%) & 1 Session, N (\%) & $\geq 2$ Sessions, $N(\%)$ & $P$ Valuea \\
\hline Neither agree or disagree & $101(23)$ & $45(22)$ & $56(25)$ & \\
\hline Disagree/strongly disagree & $86(20)$ & $53(25)$ & $33(15)$ & \\
\hline \multicolumn{5}{|c|}{ Patient was more likely to participate in other Kaiser Permanente programs after wellness coachingb } \\
\hline Agree/strongly agree & $235(54)$ & $99(48)$ & $136(60)$ & \multirow{3}{*}{.004} \\
\hline Neither agree or disagree & $134(31)$ & $67(32)$ & $67(30)$ & \\
\hline Disagree/strongly disagree & $63(15)$ & $41(20)$ & $22(10)$ & \\
\hline
\end{tabular}

a Determined by a $x^{2}$ test for the difference in proportions between patients with 1 session and those with 2 or more sessions.

b Denominators for percentages are total responses in the category, not total survey respondents.

Table 3. Mean Patient Activation Measure 6 Score by Satisfaction and

Perceived Success Response Level Among Respondents $(n=446)$ to the

Kaiser Permanente Wellness Coaching Program Survey, Northern California, 2011

\begin{tabular}{|c|c|c|}
\hline Characteristic & PAM-6 Score, Mean (SD) & $P$ Valuea \\
\hline \multicolumn{3}{|c|}{ Satisfaction outcomes } \\
\hline \multicolumn{3}{|c|}{ Patient's overall satisfaction with the service received from the wellness coach } \\
\hline Satisfied/extremely satisfied & $66.9(17.5)$ & \multirow{3}{*}{$<.001$} \\
\hline Neutral & $57.8(15.7)$ & \\
\hline Dissatisfied/extremely dissatisfied & $55.6(15.0)$ & \\
\hline \multicolumn{3}{|c|}{ Patient would recommend wellness coaching to a family member, friend, or colleague } \\
\hline Agree/strongly agree & $65.8(17.6)$ & \multirow{3}{*}{$<.001$} \\
\hline Neither agree or disagree & $58.9(14.1)$ & \\
\hline Disagree/strongly disagree & $59.1(18.4)$ & \\
\hline \multicolumn{3}{|c|}{ Patient reported the number of sessions offered was adequate } \\
\hline Yes & $67.4(17.8)$ & \multirow{2}{*}{$<.001$} \\
\hline No & $58.2(15.8)$ & \\
\hline \multicolumn{3}{|c|}{ Patient reported the amount of time spent with the coach was adequate } \\
\hline Yes & $65.3(17.3)$ & \multirow{2}{*}{$<.001$} \\
\hline No & $56.5(16.0)$ & \\
\hline \multicolumn{3}{|c|}{ Perceived success outcome } \\
\hline \multicolumn{3}{|c|}{$\begin{array}{l}\text { Patient reported wellness coaching helped for a weight-related goal (among those who discussed a } \\
\text { weight-related topic) }\end{array}$} \\
\hline Yes & $66.3(17.4)$ & \multirow{2}{*}{$<.001$} \\
\hline No & $56.2(15.3)$ & \\
\hline \multicolumn{3}{|c|}{ Other outcome } \\
\hline \multicolumn{3}{|c|}{ Patient was more aware of Kaiser Permanente resources after wellness coaching } \\
\hline Agree/strongly agree & $65.3(17.3)$ & \multirow{3}{*}{.003} \\
\hline Neither agree or disagree & $61.6(16.0)$ & \\
\hline Disagree/strongly disagree & $58.2(18.1)$ & \\
\hline
\end{tabular}


Preventing Chronic Disease | Patient Satisfaction and Perceived Success with a Teleph... Page 12 of 12

Abbreviation: PAM, Patient Activation Measure 6 (24); SD, standard deviation.

a Determined by either a $t$ or $F$ test for the difference in mean PAM- 6 scores by patient response.

The opinions expressed by authors contributing to this journal do not necessarily reflect the opinions of the U.S. Department of Health and Human Services, the Public Health Service, the Centers for Disease Control and Prevention, or the authors' affiliated institutions.

5. The RIS file format is a text file containing bibliographic citations. These files are best suited for import into bibliographic management applications such as EndNote 圈, Reference Manager 国, and ProCite 圈. A free trial download is available at each application's web site.

For Questions About This Article Contact pcdeditor@cdc.gov

Page last reviewed: October 31, 2013

Page last updated: October 31, 2013

Content source: National Center for Chronic Disease Prevention and Health Promotion

Centers for Disease Control and Prevention 1600 Clifton Rd. Atlanta, GA 30333, USA

80o-CDC-INFO (80o-232-4636) TTY: (888) 232-6348 - Contact CDC-INFO

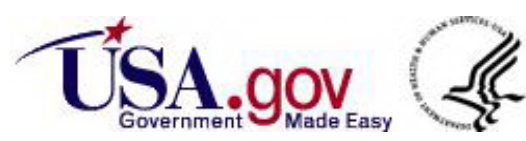

